\title{
Research of a Certain Aero Winch Test System
}

\author{
Zhang Wenjun \\ Aeronautic Repair Engineering Department \\ The First Aeronautical Institute of Air force,FAIAF \\ Xinyang,China,13693760806 \\ zwjxs2011@163.com \\ Chen Guijun \\ Foreign Training Department \\ The First Aeronautical Institute of Air force, FAIAF \\ Xinyang,China,13523763982
}

\begin{abstract}
- the performance of the aero winch which is installed on the helicopter affects the flight performance and flight safety. In order to conduct intelligent test of the aero winch, we researched a certain aero winch test system, this paper presents the hardware and software of the system, explains the operation principle, and introduces the solutions for the main technical difficulties.
\end{abstract}

Key words-aero winch;test system; helicopter

\section{INTRODUCTION}

The aero winch is used on the helicopter extensively, it can be used for lifesaving and cargo lifting, and its performance affects the flight performance and flight safety of the helicopter. So the single performance and the overall system of the electric winch and its parts must be tested to check its function can satisfy the technical requirements or not after leaving the factory, phase inspection and overhauling. To solve the difficulty of helicopter aero winch test, we designed an aero winch test system based on torque-rotational speed sensor, this system has many advantages, such as high intelligence, reliable performance, and easy to operate.

\section{HARDWARE COMPOSITION AND OPERATION PRINCIPLE}

The certain aero winch is electric winch, the hardware of the test system is divided into three parts mainly: computer and interface control board, ports adapter, and the winch test drive console, the composition principle is shown in Figure 1.

\author{
Li Qingfeng \\ Training Department \\ The First Aeronautical Institute of Air force, FAIAF \\ Xinyang,China,18937669681
}

Lang Juanfang

Aeronautic Repair Engineering Department

The First Aeronautical Institute of Air force, FAIAF

Xinyang,China,13323760876

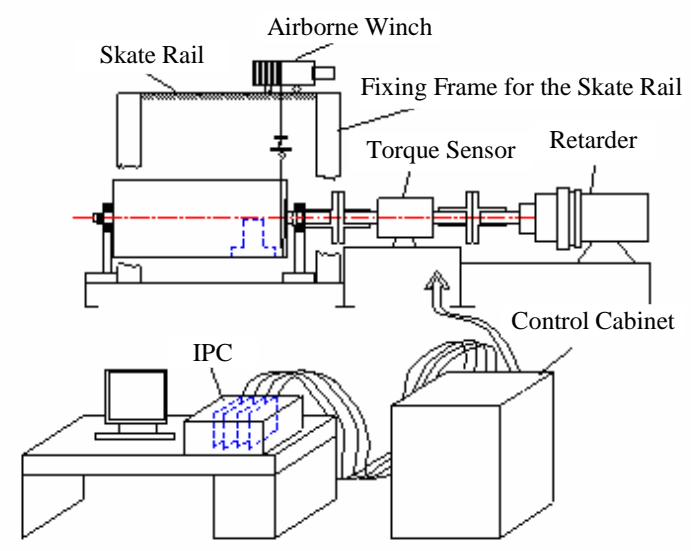

Figure1. Diagram of Hardware Composition Principle of Aero Winch Tester

These three parts are connected through various kinds of electrical signals, the operation principle is shown in Figure 2.

The computer and interface control board mainly consist of IPC (Industrial Personal Computer) system and computer interface control board. IPC system consists of mainframe, display, keyboard, mouse and so on. Interface control board consists of input board and output board of various I/O and analog quantities, stepper motor control board and torque speed acquisition board. The main function of the computer and interface control board is making the computer control the signal acquisition and loading of the controlled equipment.

Ports adapter mainly consists of stepper motor drive, torque motor controller, DC /AC contactor, relay, power supply and switches. It is the bridge between computer interface control board and controlled equipment.

The winch test drive console mainly consists of torque motor, torque-rotational speed sensor, winding plate, winch installation follow-up platform and so on. Its main function is making the steel rope wind automatically and loading the steel rope load. 


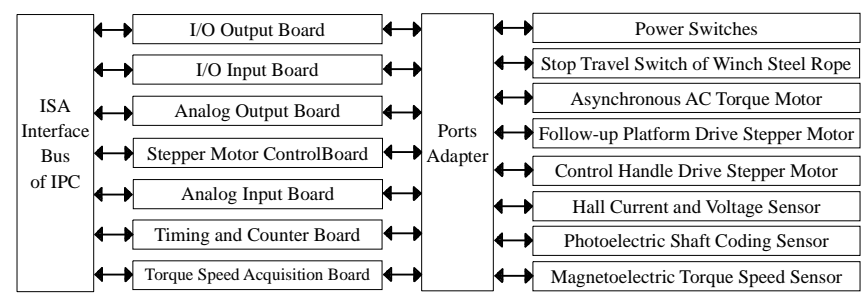

Figure 2. Operation Principle of the Certain Aero Winch Tester

\section{SOFTWARE COMPOSITION AND OPERATION PRINCIPLE}

The operating system platform of the software uses Windows 2000, the developing platform takes Lab Windows/CAI, and the data is processing by VFP and other tools[1]. The software mainly consists of system initialization module, master control module, performance test operation module, data management module, instrument and equipment drives, signal real time acquisition module, troubleshooting module. The composition principle diagram is shown in Figure 3.

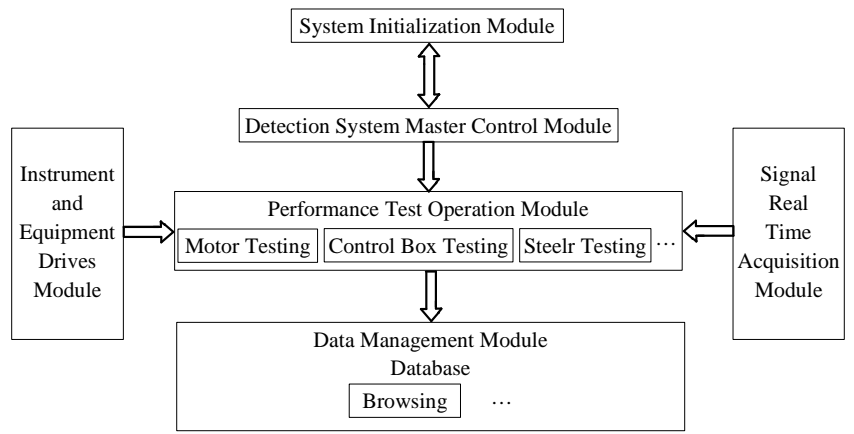

Figure 3. The Software Basic Composition Principle Diagram of the System

To make a good open software system, add new TPS flexibly and conveniently according to the requirement of the new equipment which it will be tested, we developed the modularization general test software based on database, and controlled the test flows through database. The basic steps of operating the test procedures can be summarized as: calling interactive user interface; opening the database and reading the test flows according to the test requirements set by user interface; starting the corresponding test functions according to the test flows, conducting the data configuration, data acquisition, analyzing and calculating, and then store the test result into the database; starting the database management module, and browsing, modifying, printing, troubleshooting the test results, and then transferring the test results to the interface as the requirement of the user.

The data of real time collected by the system and field test is programmed by LabWindows CVI, but the data processing and expert system are developed by VFP, so these two platforms need to be connected. Because the CVI and VFP themselves don't have data interfaces, we operate the database with C language when designing, and have developed dedicated data interfaces for LabWindows CVI and VFP[2].

\section{FOR TECHNICAL DIFFICULTIES}

As the requirement of the electrical winch function test, the tension and liner speed of the steel rope must be controlled and keep constant. For this problem, we will just analyze from bench winding plate (drove by AC torque motor of test platform) rolling up steel rope, airborne electrical winch (drove by DC motor of the winch) rolling out steel rope. Since the airborne electrical winch winding plate rolls the 95-meterlong steel rope as 5 layers, the diameter will become smaller continuously when rolling out, but the test platform winding plate rolls the 95-meter-long steel rope as 1 layer, the diameter will keep the same when rolling in. It's not hard to see that keeping the tension and liner speed of the steel rope constant is difficult. To solve this problem, we developed a technology of torque motor control and applied it into this electrical winch test.

\section{A. Constant-power Control of the Torque Motor}

The AC torque motor is a dedicated motor designed by us. To make the tension and liner speed of the steel rope keep constant, we must keep $\mathrm{P}=\mathrm{F} \cdot \mathrm{v}=\mathrm{M} \cdot \mathrm{n}=$ Constant ( $\mathrm{P}=$ = Power , $\mathrm{F}=$ Tension, $\mathrm{v}=$ liner speed, $\mathrm{M}=$ Torque , $\mathrm{n}=$ Rotation Speed ) when designed the hardware, that means we must keep the torque motor work with a constant-power. Figure 4 are matching curves of torque speed characteristics of the test platform AC torque motor and winding tension, $\mathrm{M}$ indicates Torque and $\mathrm{n}$ indicates Rotation Speed, the winding characteristics within shadowing part which intersected by the two curves in the chart are perfect, that means the relative power can be approximately constant when rotation speed kept in a range of $1 / 3 n_{0}-2 / 3 n_{0}\left(n_{0}\right.$ indicates synchronous rotational speed). So, to achieve constant-power control of the torque motor, we must kept the torque-rotational speed characteristics curve of the torque motor matching with the winding tension characteristics curve. Therefore, we take the following two measures to solve this problem when designed the system. The first is making the torque and rotation speed of the torque motor can be wide-range controlled simultaneously, and adjust the torque and rotational speed to the shadow part between the two intersection curves in the Figure 4 to get an ideal winding characteristic; the second is designing a specialized torque motor controller, and making a closed-loop control of torque motor together with the torque-rotational speed sensor, thus can make a constant-power control of the torque motor.

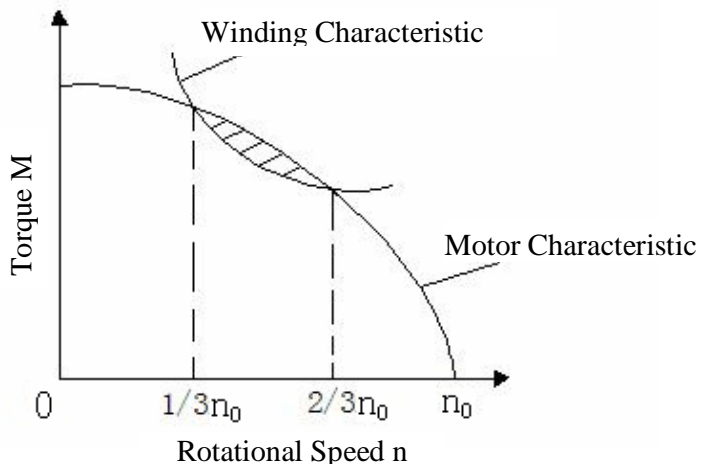

Figure 4. Matching Curve of Torque Speed Characteristic and Tension 


\section{B. Wide-range Controlling the Torque and Rotation Speed of the Torque Motor Simultaneously}

The torque speed characteristic (mechanical characteristic) of the general three-phase asynchronous motor is showing in Figure 5, nm means rotation speed with maximum torque, and it is also the boundary of the "steady part" and "unsteady part" of the motor mechanical characteristic. We can treat the $\mathrm{nm} \sim \mathrm{n} 0$ section as steady operation part, and treat the $0 \sim \mathrm{nm}$ section as unsteady operation part. "Steady" means supposing that the motor was operating on point 1 of the "steady part", if the motor torque is smaller than load torque when load torque $\mathrm{MH}$ increased to $\mathrm{MH}^{\prime}$ for some reason, the motor begins to slow down, but with decreasing of the rotation speed, the output torque of the motor begins to increase, the motor will operate on point 2 steadily until the torque keeping a balance with $\mathrm{M}_{\mathrm{H}}{ }^{\prime}$, the rotation speed is $\mathrm{n}_{2}\left(\mathrm{n}_{2}<\mathrm{n}_{1}\right)$.

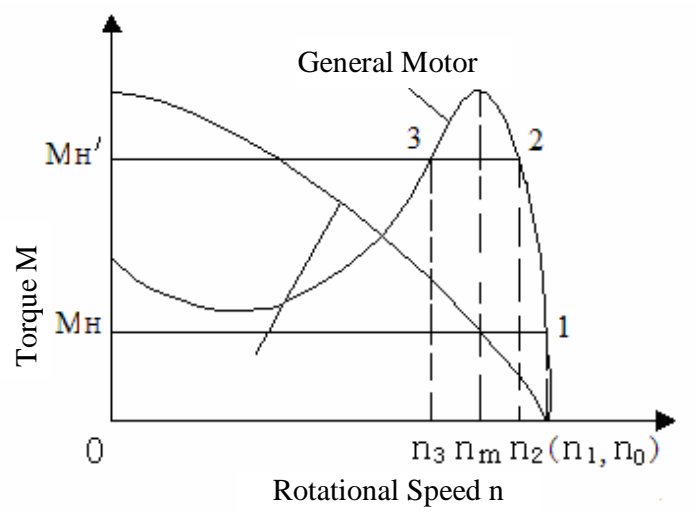

Figure 5. The Torque Speed Characteristic of the Three-phase Asynchronous Motor

Phase $0 \sim \mathrm{n}_{\mathrm{m}}$ is unsteady operation area, that's also means the crossing point 3 of mechanical characteristic and load torque in this phase are unsteady. Since the rotation speed on point 3 increases slightly which affected by some outside reasons, the torque will exceed load $\mathrm{MH}^{\prime}$ and increase the speed of the motor, finally it will operate with rotation speed n2 on point 2 of thTớâuêe Mototor r se. Otherwise, if the rotation speed on point 3 decreases sulgntly which affected by some outside reasons, the torque will be lower than load and the speed of the motor will be decreased to 0 .

This proves that the speed of the motor can just change in the limited range between $\mathrm{nm}$ and $\mathrm{n} 0$, if needs to enlarge this range, we must shift the maximum torque point $\mathrm{n} 0$ left. Our torque motor was designed according to this principle, the maximum torque always appears near the locked-rotor, see Figure 6, the steady operation range is quite large, it can operate steadily from close synchronous speed to the near locked-rotor. So, it can satisfy the requirements of the test very well, even including the condition of working for 5 minutes under the locked-rotor situation continually with $4050 \mathrm{~N}$ of tension, and it is an ideal supporting device for the test system.

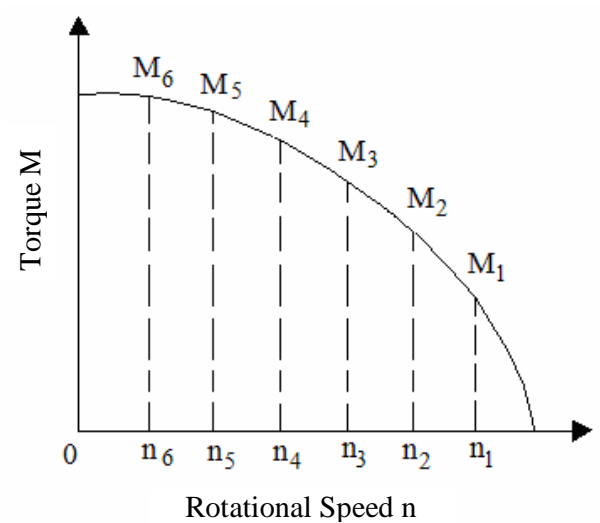

Figure 6. Torque-rotational Speed Characteristic of the Torque Motor

\section{Continuous adjustment of the Supplying Power of the} Torque Motor

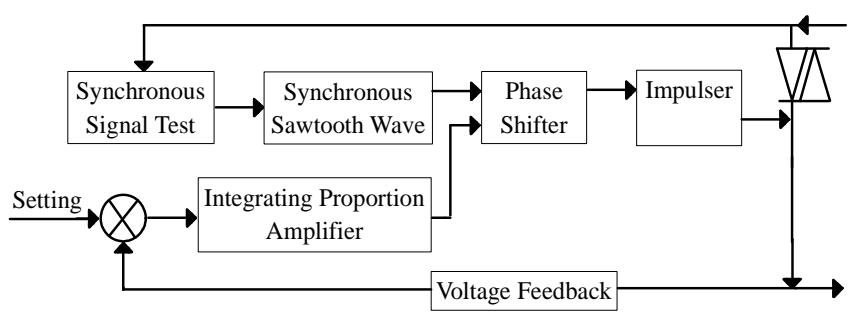

Figure 7. The Principle Diagram of Torque Motor Controller

The dedicated torque motor controller changes the conduction angle of the AC which flowing through the motor by bidirectional thyristor, and making the supplying power of the torque motor can be adjusted continuously. The controlling circuit can balance the three-phase output current automatically with tracking automatic control method through three-phase network phase synchronized control, and protect the motor voltage adjustment in operation from runaway effectively through output feedback control. At the same time, ensure the output three-phase voltage and current can be balanced automatically with three-phase voltage automatic synchronous phase-shifted control method, and making the power of torque motor becomes constant. The control principle diagram is shown in Figure 7, the voltage feedback in the diagram is real-time signals of torque and rotation speed which are acquired by torque-rotational speed sensor, and output $0 \sim 10 \mathrm{~V}$ voltage controlled by the computer $\mathrm{D} / \mathrm{A}$, the voltage is in direct proportion to the output power of the motor. Adding this voltage to the voltage feedback port of the controller, it can realize constant-power control by the computer automatically.

\section{REFERENCE}

[1] [1] Ning Dong, Li Hongjuan. The Aero Computer System and Application[M]. Xi'an: Northwest University of Technology Press, 2002.

[2] [2] Li Xingshan, Zuo Yi. Automatic Test System Integration Technology[M]. Bei Jing: Electronic Industry Press, 2004. 